\title{
Yield of ischaemic exercise electrocardiograms in relation to exercise intensity in a normal population
}

\author{
Gordon R. Cumming ${ }^{1}$ \\ From The University of Manitoba and The Children's Hospital of Winnipeg, Manitoba, Canada
}

Maximal bicycle ergometer exercise in an asymptomatic male population, aged 40-65 years, revealed 63 subjects with 'ischaemic' ST changes. The work intensity at the time of appearance of this change was expressed as actual heart rate as a per cent of maximum heart rate, and oxygen uptake as a per cent of maximal oxygen uptake. If the exercise had been stopped at a target heart 'rate of 85 per cent of expected maximum heart rate, half of the abnormal responses would have been missed. The evidence favours the use of a graded exercise test proceeding to the point of voluntary fatigue. The ischaemic change was noted only during and/or after a supermaximal exercise load in 27 per cent of the subjects.

With exercise electrocardiography being used vin population surveys to detect asymptomatic coronary heart disease, it is important to know the influence of the level of exercise stress on the yield of positive tests. The Masters step test has had the advantage of simplicity, uniformity, and years of practical experience, and is now being supplanted in many centres by 2multistage tests that stress the subject to a defined end point which can be: subjective symptoms such as fatigue or chest pain; signs of distress such as dyspnoea or disorientation or failing co-ordination; electrocardiographic changes such as ischaemic changes or ventricular arrhythmias; or the reaching of a tar; get heart rate. Stopping exercise at a target heart rate has the advantage of avoiding exerwise to extreme fatigue, and may have added (but yet unproven) safety benefits. Tests requiring maximal or near maximal exercise, on the other hand, result in the recognition of more subjects with an ischaemic type pattern, and may therefore be of greater value in defining subjects at risk for developing coronary heart disease. While information is available to indicate the advantage of near maximal tests over the Masters test (Doan et al., 1965), data are not available on the yield of positive tests with exercise intensities ranging from 60 to IoO per cent of maximum. We have reviewed 63 positive exercise tests found in a

\footnotetext{
Received 20 December I97 I.
}

1 Supported by a Dominion-Provincial Health Grant. population survey (Cumming, Borysyk, and Dufresne, 1972), and have correlated the occurrence of ischaemic ST changes with various indices of exercise intensity.

\section{Subjects and methods}

Five hundred and ten male volunteers, 40-65 years of age, were contacted through the personnel office of the City of Winnipeg. Those with angina or previous myocardial infarction or valvular heart disease were excluded. Each employee had a cardiovascular examination and resting electrocardiogram. The exercise test consisted of two 6-minute submaximal loads on an electrically braked ergometer (first load $300-600 \mathrm{kpm} / \mathrm{min}$, second load 600-1050 kpm/min). From the heart rate response to the submaximal load, a supermaximal load was selected on the basis of a normogram (Astrand, I960) that would have required an oxygen uptake exceeding the predicted maximal oxygen uptake $\left(\mathrm{V}_{\mathrm{O}_{2}} \max \right)$ by about ro per cent. This last load was continued for 2.5 to 5 minutes, and the intensity was adjusted, if necessary, so that the subject completed at least 2.5 minutes of the final load, finishing fairly exhausted. Oxygen uptake was measured continuously during the maximal load and during the latter part of each submaximal load using a continuous system consisting of a paramagnetic oxygen analyser, carbon dioxide analyser, calibrated dry test meter, and an ultraviolet oscillographic recorder. The maximal load was omitted in 147 subjects because of one or more of the following: patient motivation, orthopaedic problems, leg cramps, electrocardiographic changes of 
ST depression or frequent ventricular extrasystoles, lack of physician in immediate test area. Of the 363 subjects who worked the third load, a value for oxygen uptake close to $\dot{V}_{2}$ max was obtained in 338 subjects according to the attainment of one or more of four arbitrary criteria (exercise respiratory quotient over $1 \cdot 12$, blood lactate over $8.0 \mathrm{mMol} / \mathrm{l}$, heart rate within 5 beats of maximal for age, $\dot{\mathrm{V}} \mathrm{O}_{2}$ less than 90 per cent of expected for work load).

A simple bipolar chest lead from manubrium to the $\mathrm{V}_{5}$ position (MC5) was recorded on a direct writing instrument exceeding the American Heart Association specifications (1967). Electrocardiographic tracings were obtained at 2, 4, and 6 minutes of each submaximal exercise load, during the last 20 seconds of maximal exercise, and the first 20 seconds recovery. Further recovery records were recorded at 2 and 5 minutes after cessation of exercise. An example of a positive test is shown in the Fig. Criteria for a positive test were (I) ST depression of at least $0 . \mathrm{I} \mathrm{mV}$ with a horizontal or downsloping ST segment; (2) in subjects with minor ST and T wave changes at rest, a further $0.1 \mathrm{mV}$ ST depression with a horizontal or downsloping ST segment; and (3) a conspicuous ST depression of over $0.2 \mathrm{mV}$ with a slowly ascending ST segment such that the segment was still at least $0.1 \mathrm{mV}$ below the isoelectric point at the onset of the $T$ wave and the slope of ascent of ST was less than $\mathrm{I} \cdot 0 \mathrm{mV} /$ second. Valid reasons for including the latter criterion have been discussed by others (Scandinavian Committee, 1968; Punsar, Pyörälä, and Siltanen, 1968).

The population value for maximal heart rate was taken from a previous unreported study of 350 normal subjects in our laboratory, aged 20 to 82 years. Maximum heart rate declined with age according to the formula (maximum heart rate = $210-0.788$ age in years) and values are listed in Table I. The values are similar to those of several published reports with the exception of those reported by Lester et al. (1968).

\section{Results}

Positive exercise electrocardiographic changes, according to the defined criteria, occurred in 63 subjects, with the age breakdown indicated in Table 2. Positive tests occurred in 4 per cent of subjects under 45 , and in 37 per cent of subjects over 60 years of age.

The time of appearance of the ischaemic change in relation to exercise intensity is summarized in Table 3 . In 13 per cent of the subjects (group $\mathrm{Ar}$ ), the ischaemic pattern was seen only during maximal work or in the first 20 seconds after maximal work. In another I4 per cent of the subjects (groups A2 and A5) an ischaemic pattern was noted after maximal exercise, and it is not known whether the same change might have occurred during recovery from submaximal exercise alone.

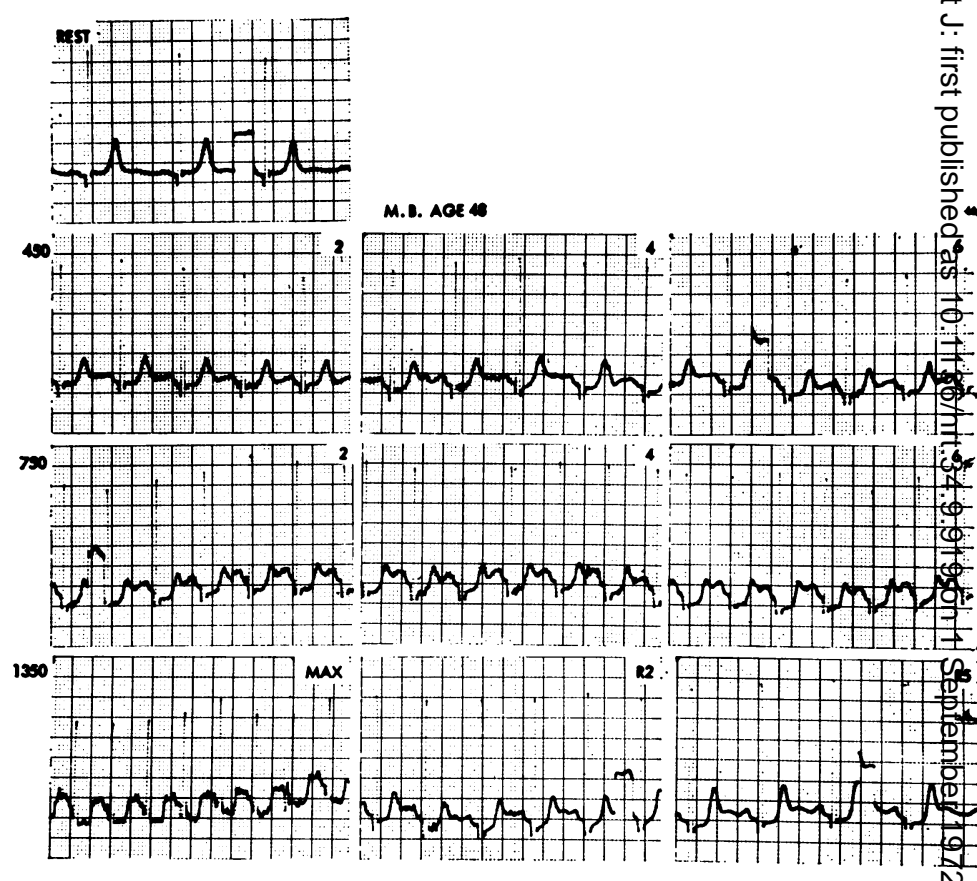

FIG. Lead MC5 at three levels of work450, 750, and $1350 \mathrm{kpm}$. Slight ST depression after 6 minutes of work at $450 \mathrm{kpm} / \mathrm{min}$. Positive test after 6 minutes work at $750 \mathrm{kpm} / \mathrm{min}$. Worked 3 minutes at $1350 \mathrm{kpm}$ with $4 \mathrm{~mm}$ $S T$ depression. Normal at 2 and 5 minutes recovery.

Therefore, maximal exercise was required to demonstrate from 13 to 27 per cent of the ischaemic changes. In 73 per cent of the subjects, the ischaemic change was noted during and/or after submaximal exercise.

The heart rate at the appearance of the ischaemic change is given in Table 4. In about half of the subjects, the change was noted at heart rates of under 150 beats a minute, while in the remainder the positive responders

TABLE I Maximum heart rates

\begin{tabular}{lll}
\hline Age & Rate \\
\hline 40 & 182 \\
43 & 180 \\
45 & 177 \\
48 & 174 \\
50 & 172 \\
53 & 170 \\
55 & 169 \\
57 & 167 \\
60 & 165 \\
62 & 163 \\
65 & 160 \\
\hline
\end{tabular}


TABLE 2 Frequency of abnormal stress electrocardiogram by age in asymptomatic men

\begin{tabular}{llll}
\hline $\begin{array}{l}\text { Age } \\
\text { group }\end{array}$ & $\begin{array}{l}\text { No. of } \\
\text { subjects }\end{array}$ & $\begin{array}{l}\text { No. with ischaemic } \\
\text { electrocardiogra- } \\
\text { phic response }\end{array}$ & $\begin{array}{l}\text { Per } \\
\text { cent }\end{array}$ \\
\hline $40-45$ & 165 & 6 & 4 \\
$46-50$ & 149 & 16 & 11 \\
$51-55$ & 101 & 19 & 19 \\
$56-60$ & 65 & II & 17 \\
$61-65$ & 30 & II & 37 \\
\hline
\end{tabular}

- showed the first ischaemic change after the minute heart rate had exceeded 150 . The 9 subjects who showed ischaemic changes on recovery only could not be included in this or the subsequent observations.

Heart rates were expressed as a per cent of the average maximal rate for age, and the fre2. quency of ischaemic changes in the ranges of this per cent of maximal heart rate is indicated in Table 5. With exercise heart rates of less than 86 per cent of maximal, 46 per cent of the ischaemic responders would have been overlooked. About one-fifth of the subjects had reached heart rates of over 95 per cent of their predicted maximal heart rates at the appearance of the first ischaemic change. Thirteen subjects ( $21 \%$ ) developed ischaemic changes during submaximal exercise and were allowed to proceed with a supermaximal load. No arrhythmias or chest pain or untoward effects were observed in these or any of the subjects in this study.

Data on the work load at the time of the appearance of the ischaemic change are summarized in Table 6. Over 80 per cent of the abnormalities occurred at loads of $900 \mathrm{kpm} /$ minute or less. Most of the subjects requiring the high loads to reveal ischaemic changes were in the younger age brackets, but one man aged 62 years was working at $1350 \mathrm{kpm} /$ minute, and another aged 50 years at 1800

* $\mathrm{kpm} /$ minute, when the ischaemic change was first noted. The ischaemic change was noted in one-quarter of subjects at only $300 \mathrm{kpm} /$ minute of work - all of these completed an additional 6-minute load, but these subjects had low work capacities and low predicted $\dot{\mathrm{V}} \max$. values.

- Data on the oxygen uptake at the time the ischaemic change occurred, expressed as a per cent of the subject's maximum oxygen uptake (actual or predicted), are given in Table 6. Where a maximal test was performed, actual $\dot{\mathrm{V}} \mathrm{O}_{2}$ max. was used. In subjects who were not exercised maximally, $\dot{\mathrm{V}} \mathrm{O}_{2}$ max. was predicted

- from the Åstrand normogram (using the age correction factor), from the heart rate response
TABLE 3 Appearance of ischaemic changes

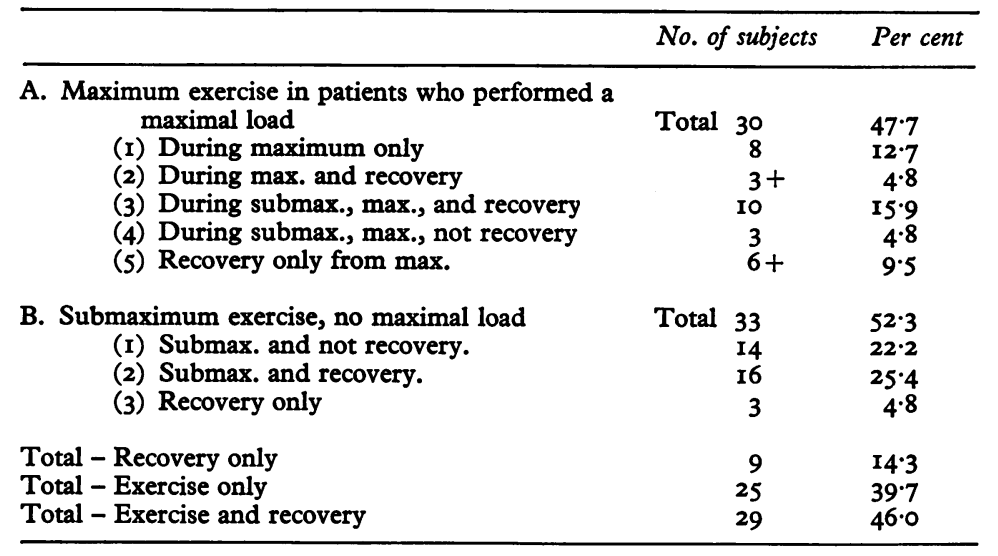

to the submaximal loads. The validity of this prediction was tested in the 24 subjects who showed ischaemic changes but who were exercised maximally. In this group, mean actual $\dot{\mathrm{V}} \mathrm{O}_{2}$ max. was $2 \cdot 42 \mathrm{l}$./minute, mean predicted $\dot{\mathrm{V}} \mathrm{O}_{2}$ max. 2.5I 1./minute, correlation coefficient 0.83 , and standard error of prediction 0.31 1./minute. From these results, if the exercise had been terminated at a $\dot{\mathrm{VO}}_{2}$ of below 75 per cent of $\max . \dot{\mathrm{V}} \mathrm{O}_{2}$, two-thirds of the positive responders would have been overlooked.

In this group of subjects, heart rate increased to maximal at a more rapid rate than the $\dot{\mathrm{V}} \mathrm{O}_{2}$ max. When heart rate, expressed as a per cent of predicted maximum heart rate, was plotted against the per cent of the maximum oxygen uptake for these 24 subjects, the correlation coefficient was 0.68 . At 85 per cent of predicted maximum heart rate, mean $\dot{\mathrm{V}} \mathrm{O}_{2}$ was only 76 per cent of maximum, with values as low as 60 per cent of actual $\dot{\mathrm{V}}_{2}$ max. being within the 95 per cent confidence limits.

\section{Discussion}

The exercise stress in our subjects was probably greater than that used in other near maximal population studies, as our subjects were encouraged to perform at a maximal level

TABLE 4 Heart rate at appearance of ischaemic change

\begin{tabular}{rrl}
\hline Heart rate & No. of subjects & Per cent \\
\hline$<125$ & 7 & $12 \cdot 9$ \\
$125-150$ & 23 & $42 \cdot 7$ \\
$151-175$ & 17 & $31 \cdot 5$ \\
$>175$ & 7 & $12 \cdot 9$ \\
\hline
\end{tabular}


TABLE 5 Heart rate at time of appearance of ischaemic change expressed as per cent of maximum heart rate

\begin{tabular}{lcllr}
\hline $\begin{array}{l}\text { Heart rate } \\
\% \text { of max }\end{array}$ & $\begin{array}{l}\text { Age } \\
40-55\end{array}$ & $\begin{array}{l}\text { Age } \\
56-65\end{array}$ & $\begin{array}{l}\text { Total } \\
\text { No. of } \\
\text { subjects }\end{array}$ & $\begin{array}{l}\text { Per } \\
\text { cent }\end{array}$ \\
\hline$<50$ & 0 & 0 & 0 & 0 \\
$51-75$ & 10 & 2 & 12 & 22 \\
$76-85$ & 6 & 7 & 13 & 24 \\
$86-95$ & 12 & 7 & 19 & 35 \\
$>95$ & 6 & 4 & 10 & 19 \\
\hline Total & 34 & 20 & 54 & 100 \\
\hline
\end{tabular}

chosen for them. In the treadmill tests used by Bruce and McDonough (1969), and by Kattus et al. (1971), the subjects were asked to stop when they were fatigued or short of breath, and these tests must be considered to be 'near maximal'. However, it is also likely that our tests did not produce maximal values for $\dot{\mathrm{V}}_{2}$ in many of the subjects for we did not try to show a plateau effect, and there is a limit beyond which it is not prudent to push a middle-aged volunteer. Even so, the mean blood lactate value obtained three minutes after exercise in our subjects was $9.6 \mathrm{mMol} / 1$. The bicycle is not as effective as the treadmill in providing a maximal aerobic stress (Shephard, I97I). We therefore regard our stress as probably being near maximal as well, despite the fact that considerable encouragement was given to the subjects to perform the supermaximal load.

Information is lacking on the relation between the intensity of exercise necessary to produce an ischaemic electrocardiographic change to the subsequent development of coronary heart disease in asymptomatic men. While changes that occur at low work loads might be expected to carry a worse prognosis, it is also possible that changes that develop at low work loads and then remain constant while the subject continues the exercise to considerably higher loads without symptoms

TABLE 6 Work load at time of appearance of ischaemic change

\begin{tabular}{lrlrl}
\hline $\begin{array}{l}\text { Work load } \\
\text { kpm/min }\end{array}$ & \multicolumn{2}{l}{ No. of subjects } & Total & $\begin{array}{l}\text { Per } \\
\text { cent }\end{array}$ \\
\cline { 2 - 3 } & Age 40-55 & Age 55-65 & & \\
\hline 300 & 6 & 7 & 13 & 24 \\
$600-750$ & 16 & 8 & 24 & 45 \\
900 & 5 & 2 & 7 & 13 \\
$>900$ & 9 & 1 & 10 & 19 \\
\hline
\end{tabular}

TABLE 7 Oxygen uptake at time of appearance of ischaemic change

\begin{tabular}{lllll}
\hline \multirow{V}{*}{$\mathrm{O}_{2}$ as } & \multicolumn{2}{l}{ No. of subjects } & $\begin{array}{l}\text { Total } \\
\text { per cent of }\end{array}$ & $\begin{array}{l}\text { Per } \\
\text { cent }\end{array}$ \\
\cline { 2 - 5 }$\dot{V} \mathrm{O}_{2}$ max & $\begin{array}{l}\text { Measured } \\
\dot{V} \mathrm{O}_{2} \text { max }\end{array}$ & $\begin{array}{l}\text { Predicted } \\
\dot{V} \mathrm{O}_{2} \text { max }\end{array}$ & & \\
\hline$<50$ & 0 & $\mathrm{I}$ & 1 & 2 \\
$5 \mathrm{I}-70$ & 5 & 2 & 7 & 13 \\
$71-95$ & 8 & 15 & 23 & 43 \\
$>95$ & 11 & 3 & 14 & 26 \\
\hline Total & 24 & 30 & 54 & 100 \\
\hline
\end{tabular}

might be of lesser significance. Long-term follow-up of a number of subjects is required to solve these problems.

A screening test should be simple to apply, safe, and acceptable to the population. The test used in our study was for research purposes and is not put forth as a practical screening method because of its duration and the maximal effort required. It has been proposed that exercise tests can be stopped at 85 per cent of maximal heart rate (Sheffield, Roitman, and Reeves, 1969), this being a reasonable compromise between patient acceptability, safety, and yield of positive information. However, if we had used this cutoff point, over half of the responders may have had negative tests indicating that the 85 per cent maximum heart rate value is not a sufficiently intense exercise load. Another drawback to using a heart rate cutoff point is the variability of maximum heart rate values in adult subjects. Our data indicated that the standard deviation for maximum heart rate at any age was at least Io beats/minute, so that the 95 per cent confidence limits of maximum heart rate at age 40 ranged from I62 to 202 beats/minute. Hence, there may be considerable error in selecting a meaningful target heart rate in any one individual without previous knowledge of the individual's actual maximal heart rate. It seems more appropriate to use a graded exercise test progressing until the subject voluntarily stops because of fatigue or dyspnoea, or the test is terminated by the observer because of electrocardiographic changes and/or other factors. Subjects need not be pushed as they were in our series and the test should be considered a near maximal test. This type of test may be performed on a treadmill (Bruce and McDonough, 1969), or a similar progressive test can be managed with the bicycle ergometer with continuous 3-minute loads beginning at $300 \mathrm{kpm} / \mathrm{minute}$ and increasing by $300 \mathrm{kpm}$ every 3 minutes until voluntary fatigue. There 
is some advantage to having work loads of at least 3 minutes' duration, as this allows an estimation of the submaximal working capacity and prediction of the aerobic power of the subjects. While a period of 6 minutes of each work load would be more desirable for this purpose, the test would be unduly prolonged for screening purposes.

The prognostic implications of ischaemic type electrocardiographic changes in asymptomatic subjects have been worked out for the Masters test (Robb and Marks, 1967), for a constant rate step test (Blackburn, Taylor, and Keys, 1970), and for a treadmill walk (Doyle and Kinch, 1970). Five-year follow-up information after maximal stress testing is available on only 22 subjects with abnormal tests, and only one myocardial infarction occurred during this follow-up (Bruce and McDonough, 1969). Needless to say, the prognostic value of changes labelled as ischaemic that are revealed only by maximal exercise require further study.

Further work is also required on the optimal lead system for population surveys. Blackburn suggests that a bipolar lead such as MC5 will allow detection of about 85 per - cent of positive responders revealed by multiple leads or a vector system (Blackburn et al., 1967), but Rautaharju and Wolf (I97I) have pointed out that an ischaemic type ST change can be found in up to roo per cent of subjects in at least one of the fifty lead systems proposed for exercise electrocardiography.

\section{References}

American Heart Association Committee on Electrocardiography (1967). Recommendations for standardization of leads and of specifications for instruments in electrocardiography and vectorcardiography. Circulation, 35, 583 .

Asstrand, I. (1960). Aerobic work capacity in men and women with special reference to age. Acta Physiologica Scandinavica, 49, Suppl. 169.

Blackburn, H., Taylor, H., and Keys, A. (1970). The electrocardiogram in prediction of five-year coronary heart disease incidence among men aged forty through fifty-nine. Circulation, 4I, Suppl. I, 154.
Blackburn, H., Taylor, H. L., Okamoto, N., Rautaharju, P., Mitchell, P. L., and Kerkhof, A. C. (1967). Standardization of the exercise electrocardiogram. A systematic comparison of chest lead configurations employed for monitoring during exercise. In Physical Activity and the Heart, p. ror. Ed. by M. J. Karvonen and A. D. Barry. Charles C. Thomas, Springfield, Illinois.

Bruce, R. A., and McDonough, J. R. (1969). Stress testing in screening for cardiovascular disease. Bulletin of the New York Academy of Medicine, 45, 1288.

Cumming, G. R., Borysyk, L., and Dufresne, C. (1972). The maximal exercise ECG in asymptomatic men: frequency of abnormal tests, relation to risk factors, possible significance. Canadian Medical Association fournal, 106, 649.

Doan, A. E., Peterson, D. R., Blackmon, J. R., and Bruce, R. A. (1965). Myocardial ischemia after maximal exercise in healthy men. American Heart Fournal, 69, II.

Doyle, J. T., and Kinch, S. H. (1970). The prognosis of an abnormal electrocardiographic stress test. Circulation, 41, 545 .

Kattus, A. A., Jorgensen, C. R., Worden, R. E., and Alvaro, A. B. (1971). S-T segment depression with near-maximal exercise in detection of preclinical coronary heart disease. Circulation, 44, 585 .

Lester, M., Sheffield, L. T., Trammell, P., and Reeves, T. J. (I968). The effect of age and athletic training on the maximal heart rate during muscular exercise. American Heart fournal, 76, 370.

Punsar, S., Pyörälä, K., and Siltanen, P. (I968). Classification of electrocardiographic $S-T$ segment changes in epidemiological studies of coronary heart disease. Annales Medicinae Internae Fenniae, $57,53$.

Rautaharju, P. M., and Wolf, H. K. (197I). Computer interpretation and classification of exercise electrocardiograms; vectorcardiographic aspects. In Proceedings of the XIth International Symposium on Vectorcardiography, New York City, 1970, p. 223. Ed. by I. Hoffman. North Holland, Amsterdam.

Robb, G. P., and Marks, H. H. (1967). Post exercise electrocardiogram in arteriosclerotic heart disease. Fournal of the American Medical Association, 200, 918.

Scandinavian Committee on ECG Classification (1968). The 'Minnesota Code' for ECG classification: adaptation to $C R$ leads and modification of the code for ECGs recorded during and after exercise. Acta Medica Scandinavica, Suppl. 48I.

Sheffield, L. T., Roitman, D., and Reeves, T. J. (1969). Submaximal exercise testing. Fournal of the South Carolina Medical Association, 65, 18.

Shephard, R. J. (197I). Standard tests of aerobic power. In Frontiers of Fitness, p. 233. Charles C. Thomas, Springfield, Illinois.

Requests for reprints to Dr. G. R. Cumming, The Children's Hospital of Winnipeg, 685 Bannatyne Avenue, Winnipeg 3, Manitoba, Canada. 